\title{
Hydrogen absorption and hydride formation in pure titanium T40 (grade 2) and TA6V ELI (grade 23) under cathodic polarization in artificial seawater
}

\author{
Alexandre POLONI ${ }^{*}{ }^{1,2}$, Abdelali OUDRISS ${ }^{1,}$ Juan CREUS $^{1}$, Cyril BERZIOU $^{1}$, Egle CONFORTO ${ }^{1}$, Catherine SAVALL ${ }^{1}$, Simon FRAPPART $^{2}$, Thierry MILLOT $^{2}$, \\ Aude MATHIS ${ }^{2}$, Xavier FEAUGAS ${ }^{1}$ \\ alexander.poloni@univ-lr.fr
}

${ }^{1}$ Laboratoire des Sciences de l'Ingénieur pour l'Environnement UMR-CNRS 7356, Université de La Rochelle, Avenue Michel Crépeau, 17042 La Rochelle, France

${ }^{2}$ Naval Group, Technocampus Océan, 5 rue de l'Halbrane, 44340 Bouguenais, France

\begin{abstract}
$\underline{\text { Abstract }}$
Different kinetics of hydrogen absorption in T40 (grade 2) and TA6V ELI (grade 23) under cathodic polarization in artificial seawater have been highlighted. These polarizations were made by applying potentials from -0.8 to $-1.8 \mathrm{~V} / \mathrm{SCE}$ in artificial seawater and NaCl solution. Four stages were identified and related in term of hydrogen ingress, hydrides formation and calcareous deposit growth. The formation of $\gamma$ and $\delta$-hydrides have been observed, localized and characterized using several techniques. On T40, hydrides form as a layer that increases the surface roughness and clusters form in the bulk after first moments of hydrogen absorption. Whereas in TA6V ELI, hydrogen is absorbed by $\beta$-phase leading to a volume expansion of this phase. Then after reaching the hydrogen solubility limit of $\beta$-phase, hydrides form on interfaces $\alpha / \beta$ or $\alpha / \alpha$ and in $\alpha$ grains. For long durations, the hydrogen ingress is limited by the subsurface hydrides and the stabilized calcareous deposit. These different steps are time depend on processes which need to be tacked into account to improve knowledge of hydrogen embrittlement in titanium alloys.
\end{abstract}

\section{Introduction}

Titanium alloys are chosen for the manufacturing of components used in a marine environment. These alloys efficiently protect themselves from any damage due to this aggressive environment by forming a stable passive film of titanium oxide $\mathrm{TiO}_{2}$. When they are used in multi-materials systems under cathodic protection, these conditions could favour the hydrogen evolution reaction (HER), which may lead to the material embrittlement by hydrides formation and/or solute/plasticity interactions $[1,2]$. Consequently, characterise the hydrogen state is a key feature to understand the hydrogen embrittlement sensitivity of titanium alloys. A commercially pure titanium single phase $(\alpha)$ T40 (grade 2 ) and a two-phase titanium alloy $(\alpha / \beta)$ TA6V ELI (grade 23) are studied in order to assess the impact of the nature of each phase on the sensitivity to hydrogen absorption in artificial seawater and on hydrogen and hydrides distribution.

\section{Materials and experiments}

Two materials were studied, the commercially pure grade 2 and the grade 23 titanium alloy. Grade 2 was received in the form of $3 \mathrm{~mm}$-thick rolled sheet from TIMET and grade 23 in the form of $6 \mathrm{~mm}$-thick rolled sheet from AUBERT \& DUVAL. Grade 2, Figure 1, presents a single $\alpha$-phase equiaxed structure with grains measuring $46 \pm 10 \mu \mathrm{m}$ and some intergranular iron inclusions $(<0,3 \%$ weight $)$. The texture analysis shows a preferential crystallographic orientation of the basal (0002) pole. The axes are perpendicular to the rolling direction (RD) with the basal pole rotated about $35^{\circ}$ toward the transverse direction (TD). Grains show strong misorientations $\left(>15^{\circ}\right)$. Additionally, it has been observed by TEM only few dislocations in $\alpha-$ grains. Grade 23, Figure 1, presents a $\alpha / \beta$ bimodal structure with a volume fraction of $\beta$-phase about $6 \%$. Primary $\alpha$ grains measure $22 \pm 5 \mu$ m, secondary $\alpha$ grains measure $9 \pm 5 \mu \mathrm{m}$ and $\beta$ grains measure approximately $1 \mu \mathrm{m}$. Macro-zones of 100 to $150 \mu \mathrm{m}$-thick are stacked all along the normal direction (ND). The dislocation density in the $\alpha$-phase is on the order of $9.4 \times 10^{13} \mathrm{~m}^{-2}$ and TEM observations highlight dislocation sub-boundaries.

Hydrogen charging conditions of samples by cathodic polarization were mainly performed in artificial seawater (ASTM-D1141) at $\mathrm{pH} 8$ and $30^{\circ} \mathrm{C}$ with potentials between $-0.8 \mathrm{~V} / \mathrm{SCE}$ and $-1.8 \mathrm{~V} / \mathrm{SCE}$. Hydrogen charging were also made with these potentials and temperature in $\mathrm{NaCl}$ solution $(35 \mathrm{~g} / \mathrm{L}) \mathrm{pH} 7$ and in $\mathrm{H}_{2} \mathrm{SO}_{4}(0.1 \mathrm{M})$ solution at $-15 \mathrm{~mA} / \mathrm{cm}^{2}$ and $25^{\circ} \mathrm{C}$ to verify some assumptions. All the samples were charged on the ND face. Hydrogen concentration was measured by thermo-desorption spectroscopy (TDS Horiba EMGA Serie) on 10x4x0.5 mm samples after specific charging steps on the side of 10x4 mm (2400-SiC polished before charging). Others hydrogen charging conditions were made on 10x10x2mm OPS polished samples. XRD (Brucker advance AXS D8 with $\mathrm{Cu}$ source) and AFM were performed on samples charged at different times corresponding to each regime of the $-1.8 \mathrm{~V} / \mathrm{SCE}$ artificial seawater absorption curve. Then, transversal surfaces were polished until OPS Master-Met vibro-polishing and observed by SEM and EBSD (FEI Quanta 200 ESEM/FEG with EBSD TSL/EDAX). TEM samples were taken parallely to the surface exposed to the cathodic charging and electro-polished with a solution composed by $70 \%$ methanol, $20 \%$ 2-butoxyethanol and $10 \%$ perchloric acid at $20 \mathrm{~V}$ until the drill by Struers TenuPol-5. TEM observations were performed with a JEOL JEM 2011 at $200 \mathrm{kV}$. 


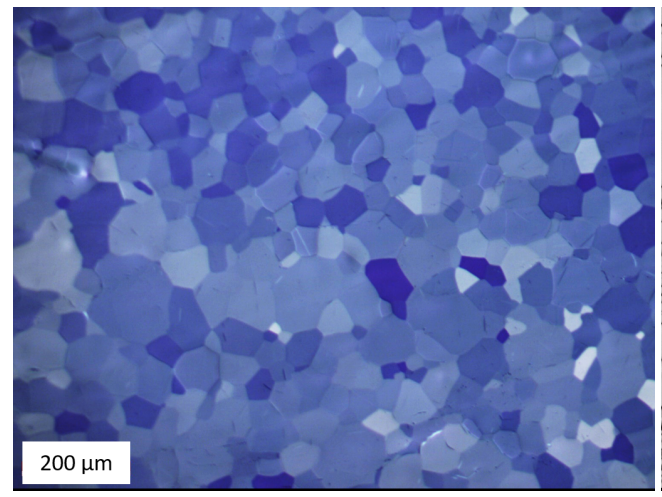

(a)

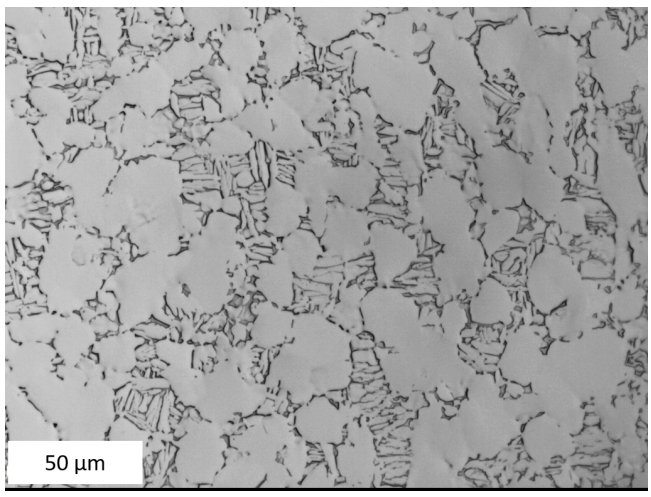

(b)

Figure 1 : Structures of our (a) grade 2 and (b) grade 23 titanium alloys observed by optical microscopy

\section{Results}

\section{Hydrogen absorption}

Figure 2 shows the evolution of hydrogen concentration in time for grade 2 and grade 23 with different cathodic potentials in artificial seawater. It is first observed that there is a significant absorption of hydrogen in these durations only with potentials equal to $-1.6 \mathrm{~V} / \mathrm{SCE}$ or more negatives. On $-1.8 \mathrm{~V} / \mathrm{SCE}$ curves, we can observe four regimes of absorption depending on time and hydrogen concentration. Hydrogen picking linearly rises with time until $30 \mathrm{~h}$ (regime I) then a quasi-plateau is observed for both alloys (regime II) at $250 \mathrm{wppm}$ for grade 2 and $300 \mathrm{wppm}$ for grade 23 . After $60 \mathrm{~h}$ for grade 2 and $72 \mathrm{~h}$ for grade 23, hydrogen uptake rises again (regime III) until the last step at $1000 \mathrm{wppm}$ after 96h for grade 2 and $2000 \mathrm{wppm}$ after $144 \mathrm{~h}$ for grade 23 (regime IV). Charging performed in $\mathrm{H}_{2} \mathrm{SO}_{4}$ for $96 \mathrm{~h}$ on grade 2 and in $\mathrm{NaCl}$ for $144 \mathrm{~h}$ on grade 23 show the same kind of behaviour but nothing can be assumed for the last step, which was not clearly reached.

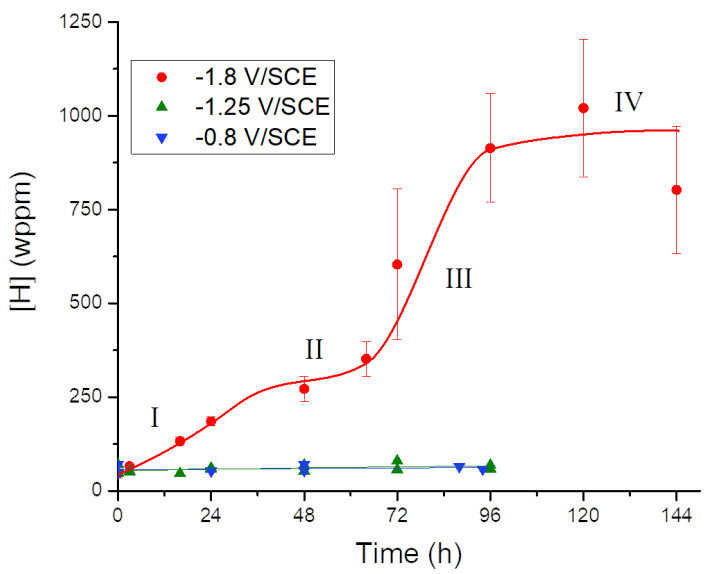

(a)

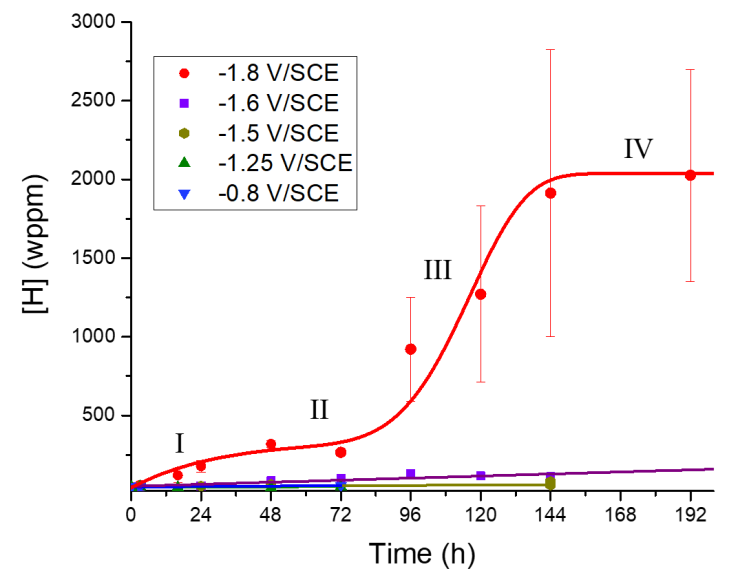

(b)

Figure 2 : Hydrogen uptake of (a) grade 2 and (b) grade 23 under cathodic polarization in artificial seawater at $30^{\circ} \mathrm{C}$ for different potentials

\section{Hydrides formation}

XRD analyses in Figure 3 were performed on samples charged at $-1.8 \mathrm{~V} / \mathrm{SCE}$ in artificial seawater for each regime of the absorption curve (Figure 2). We see the formation of $\gamma$-hydrides TiH (FCT) and $\delta$-hydrides TiHx (1.5Figure 4. Some bumps are observed on the surface and their dimensions could not allow measuring a Ra by AFM. A small evolution of the roughness of grade 23, Figure 5 is observed on regime II and an important uptake is seen on regime III. In parallel to these analyses, SEM revealed the formation of hydrides in the two alloys with the same evolution as analysed by XRD. Figure 6 shows the formation of a hydride layer on the surface of grade 2. A $2 \mu \mathrm{m}$-thick inhomogeneous layer is formed at regime I, transforming to a homogeneous $4 \mu \mathrm{m}$-thick layer at regime II and to a $16 \mu \mathrm{m}$-thick one at regime III. Hydrides have were detected around iron inclusions from regime I even in the bulk. From regime II, the formation of hydrides in all the bulk is noticed. SEM analyses performed on grade 23 (Figure 7 ) revealed the formation of hydrides from regime III. An evolution of the localisation of hydrides from the surface to the bulk is noticed. From the surface up to 100 $\mu \mathrm{m}$ in depth, intergranular and intragranular hydrides are observed, whereas only intergranular hydrides are present in the region between $100 \mu \mathrm{m}$ and $800 \mu \mathrm{m}$ in depth. From $800 \mu \mathrm{m}$ in depth to the rest of the bulk, no hydrides are identified. 


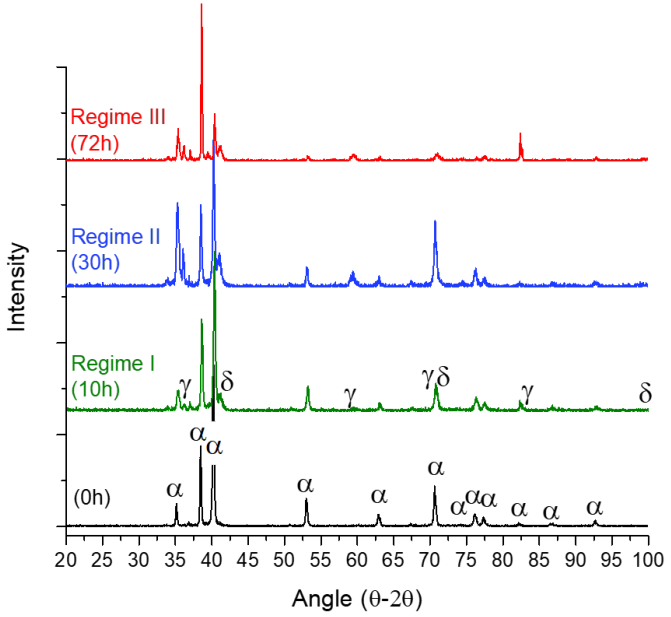

(a)

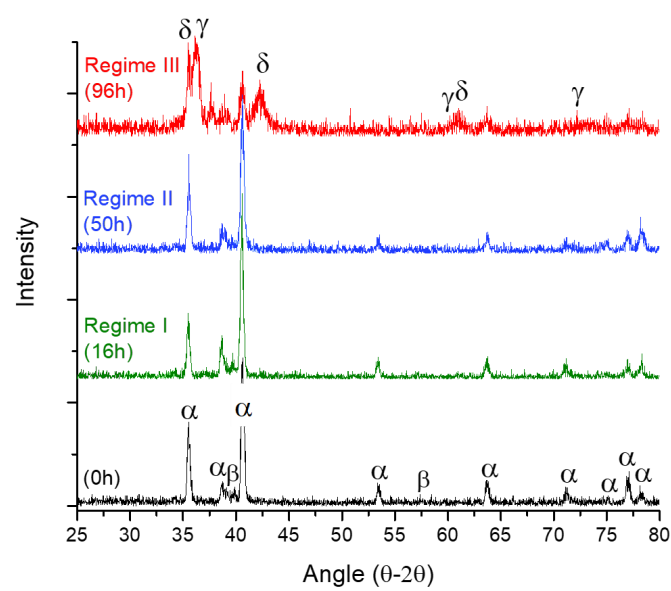

(b)

Figure 3 : XRD analyses (a) symmetric on grade 2 and (b) asymmetric $5^{\circ}$ on grade 23 after cathodic polarization at $-1.8 \mathrm{~V} / \mathrm{SCE}$ in artificial seawater

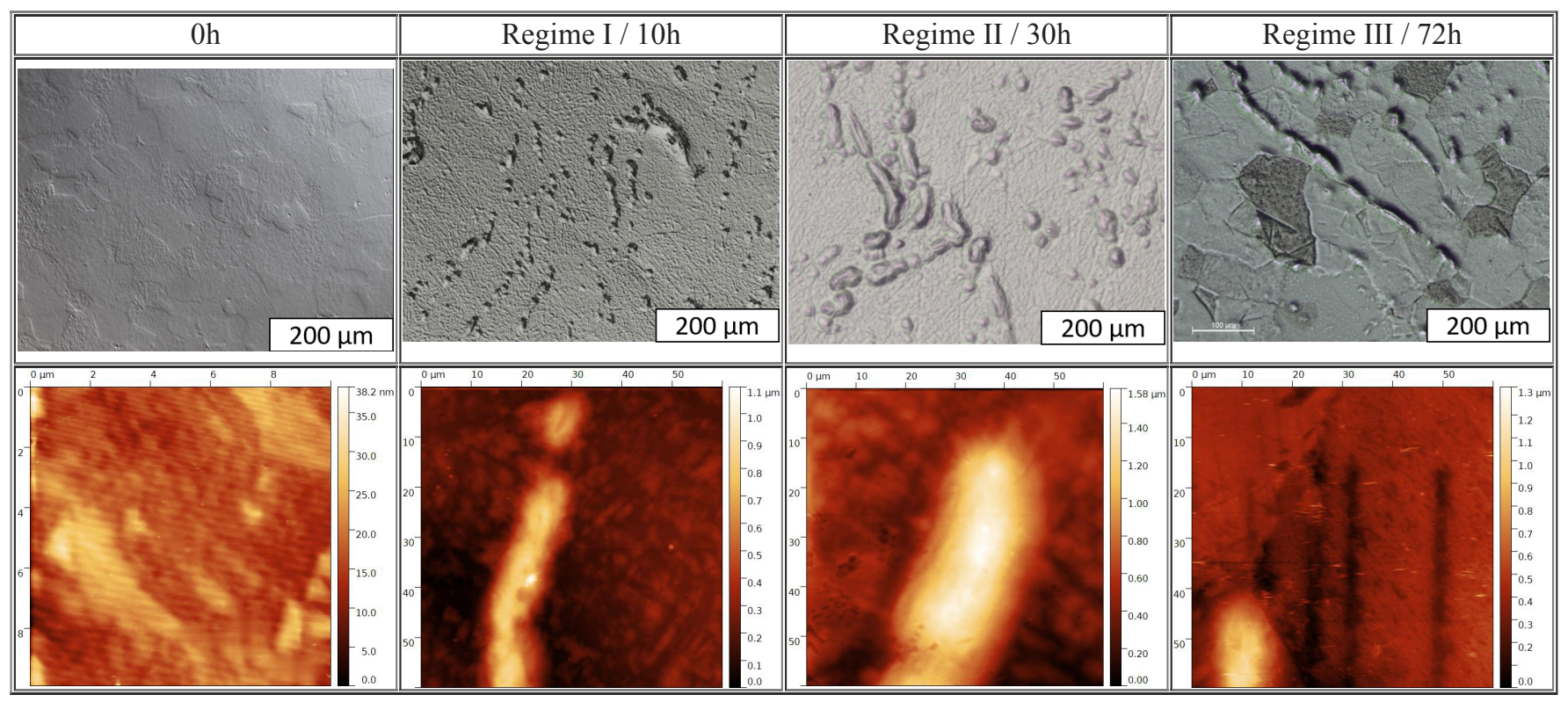

Figure 4 : Optical and AFM analyses on the exposed surface of grade 2 after cathodic polarization at $-1.8 \mathrm{~V} / \mathrm{SCE}$ in artificial seawater

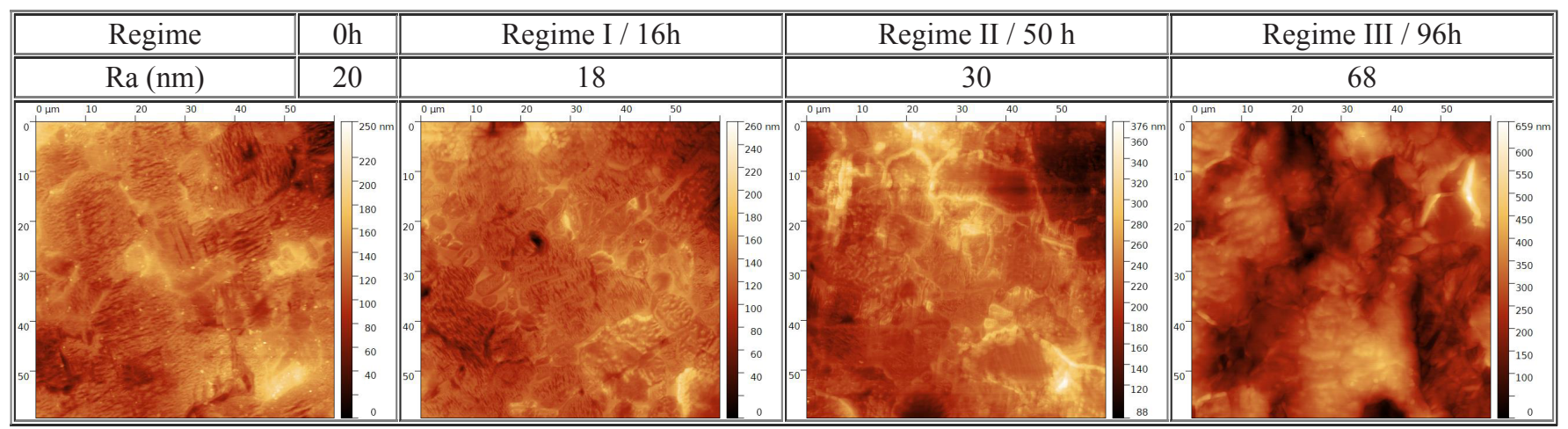

Figure 5 : AFM analyses on the exposed surface of grade 23 after cathodic polarization at -1.8V/SCE in artificial seawater 


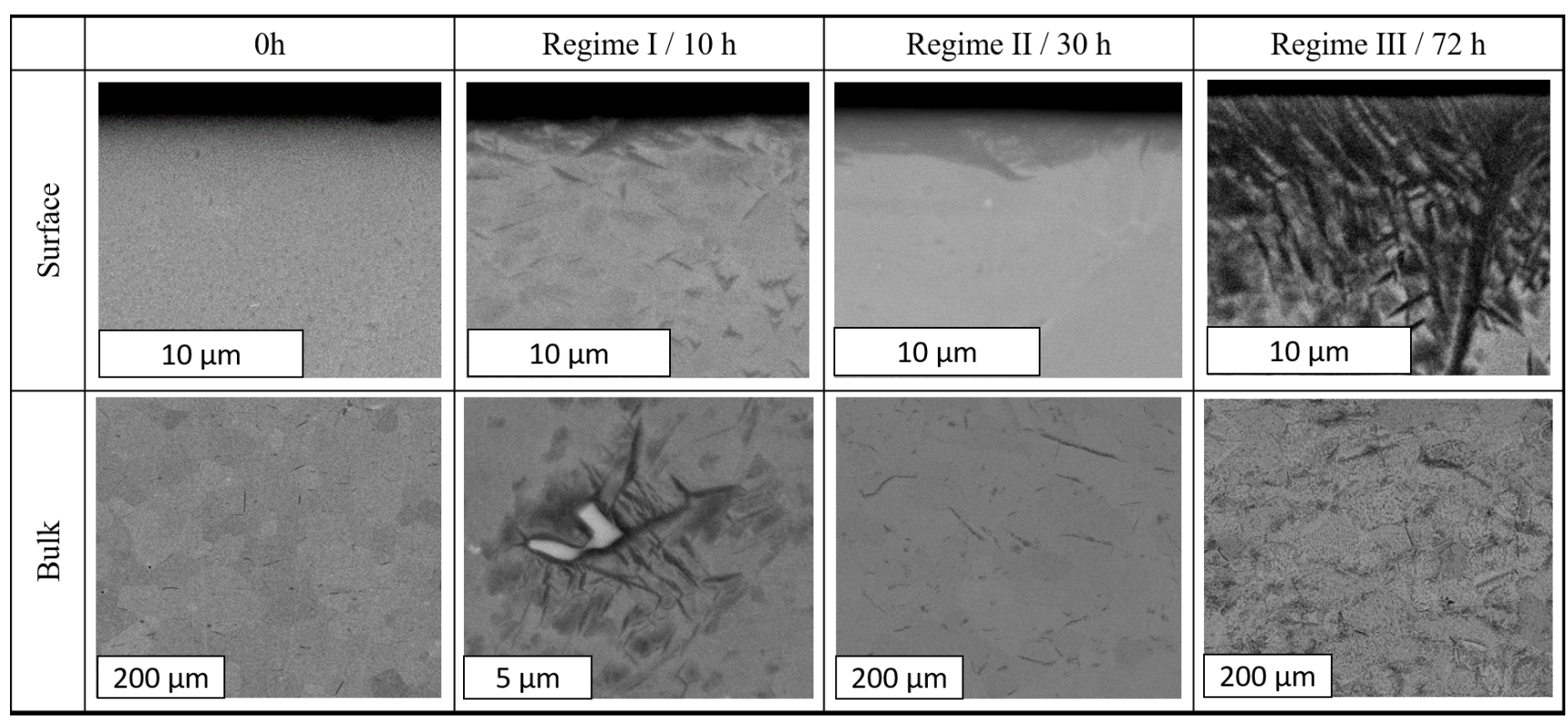

Figure 6 : SEM analyses on grade 2 without charging and charged $10 \mathrm{~h}, 30 \mathrm{~h}$ and $72 \mathrm{~h}$ in artificial seawater at $-1.8 \mathrm{~V} / \mathrm{SCE}$.
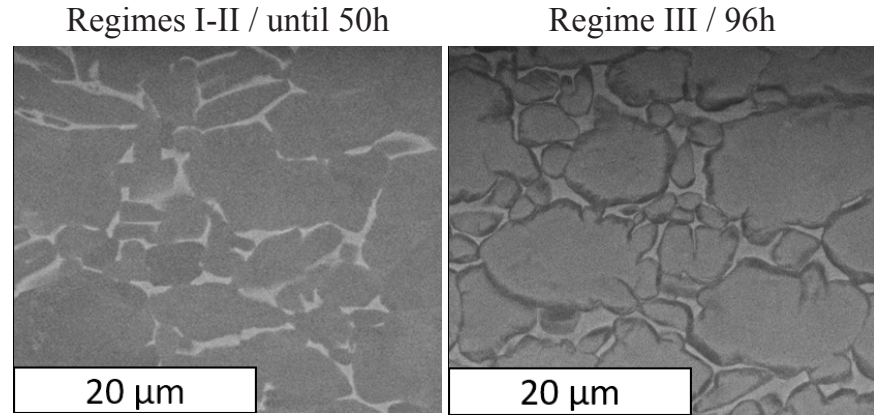

$100 \mu \mathrm{m}$

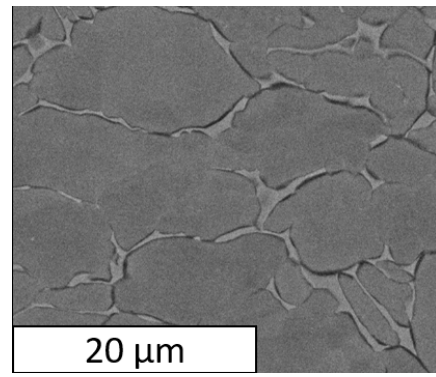

$800 \mu \mathrm{m}$
Regime IV / 144h

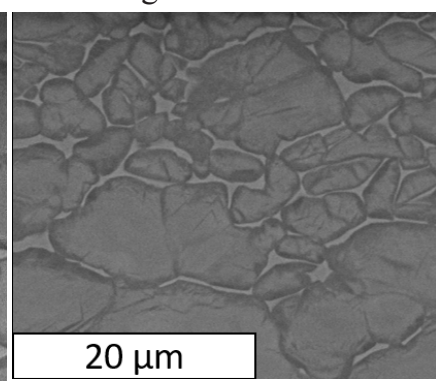

$150 \mu \mathrm{m}$

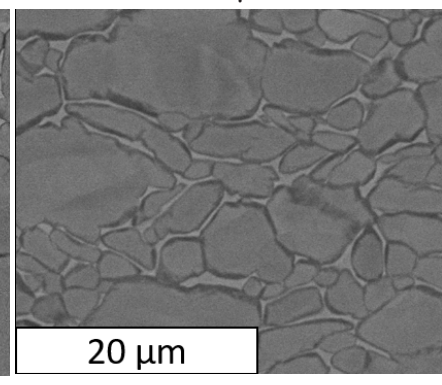

$550 \mu \mathrm{m}$
Hydrides identification

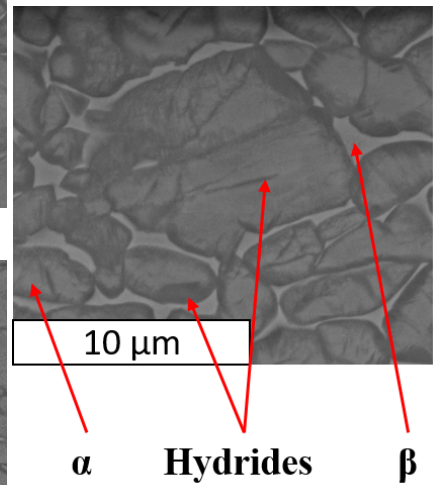

Figure 7 : SEM analyses on grade 23 charged until $50 \mathrm{~h}, 96 \mathrm{~h}$ and $144 \mathrm{~h}$ in artificial seawater at $-1.8 \mathrm{~V} / \mathrm{SCE}$. Measures represents the depth from the surface to the bulk until this kind of strucutres are seen.

TEM analyses revealed further details (Figure 8, Figure 9). On grade 2, Figure 8, the $\delta$-hydride layer grown on regime II is nanostructured and becomes homogeneous on regime III. Different orientations relationships between g-hydrides, d-hydrides and the substrate were identified [4]. $\gamma$-hydrides in OR2 were observed in regime I. In regime II, incoherent $\gamma$-hydride and $\delta$-hydrides in OR2 and OR 3 are present. The regime III revealed mainly $\delta$-hydrides in OR2 in the bulk. In grade 23, Figure 9, three kinds of hydrides were identified in regime III. First, $\delta$-hydride in OR1 grows from $\alpha / \beta$ interface toward the bulk of $\alpha$-phase. Then, $\delta$-hydride OR2 formed at the interface of $\alpha$-grain and $\beta$ grain in epitaxy [5]. Finally, $\gamma$-hydrides formed parallel to each other in OR2 with $\alpha$-grains. 

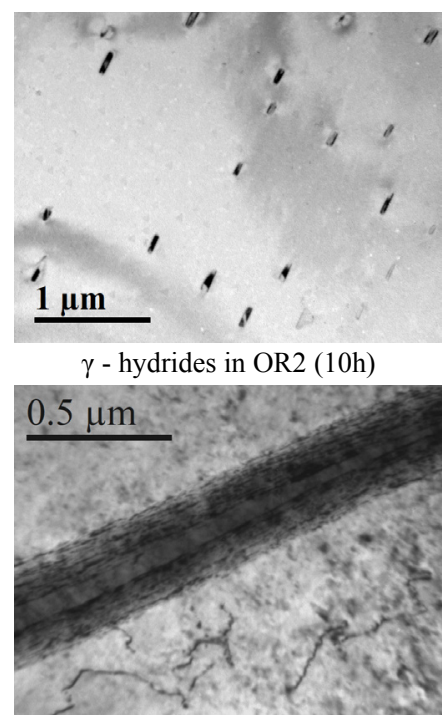

$\delta$ - hydrides in OR2 (72h)

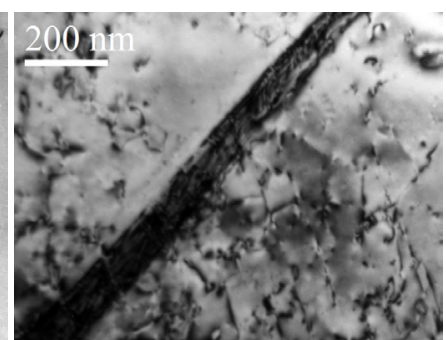

$\gamma$ - hydride (30h)

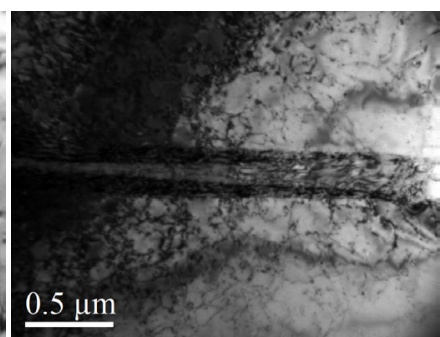

$\delta$ - hydrides in OR2 (30h)

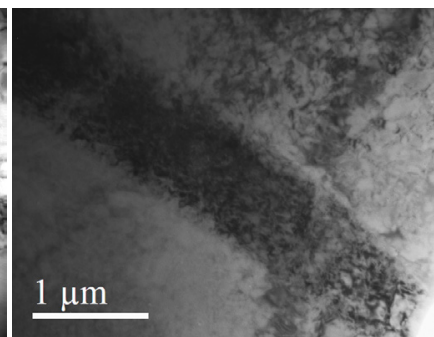

$\delta$ - hydride in OR2 (30h)

Figure 8 : TEM analyses on hydrides formed at $50 \mu \mathrm{m}$ depth in titanium grade 2 after $10 \mathrm{~h}$ (regime I), 30h (regime II) and $72 \mathrm{~h}$ (regime III) of hydrogen charging by cathodic polarization at $-1.8 \mathrm{~V} / \mathrm{SCE}$ in artificial seawater

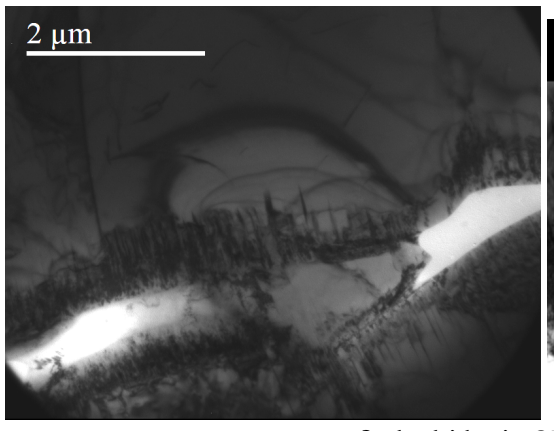

$\delta$ - hydrides in OR1, bright field

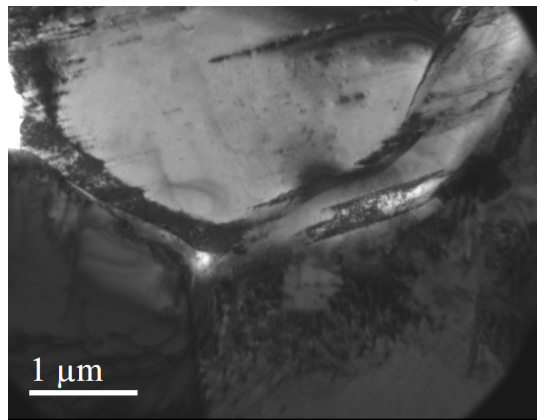

$\delta$ - hydrides in OR2, bright field

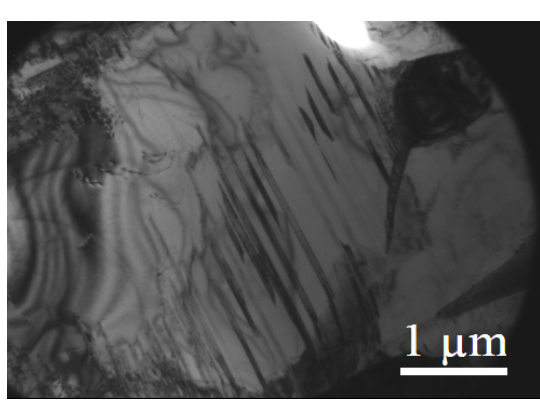

$\gamma$ - hydrides in OR2, bright field
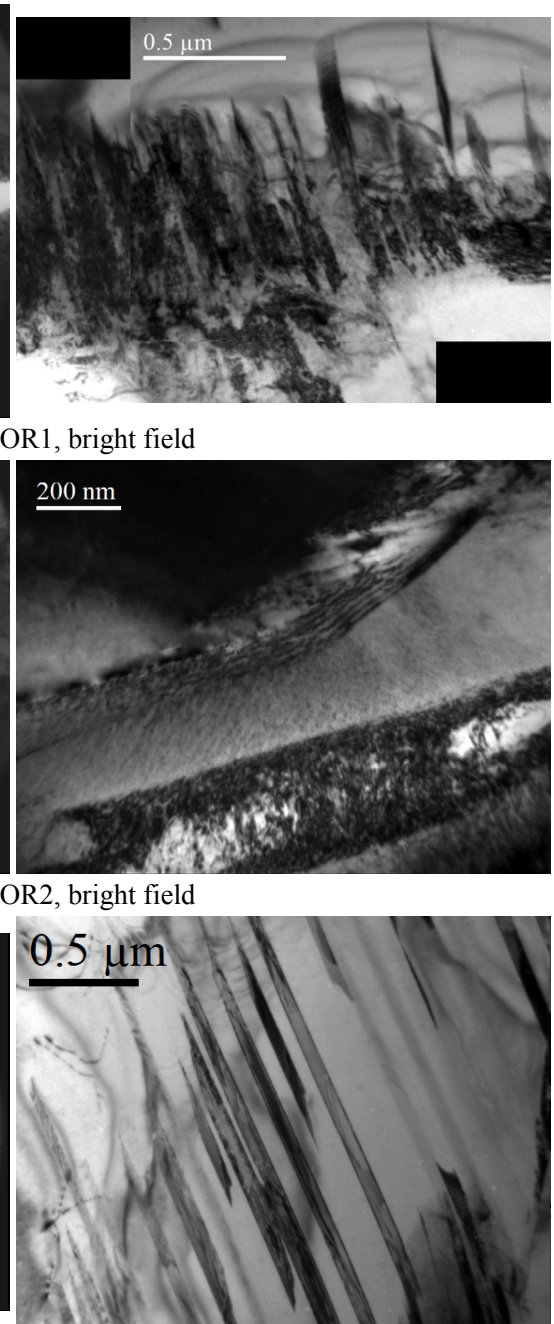

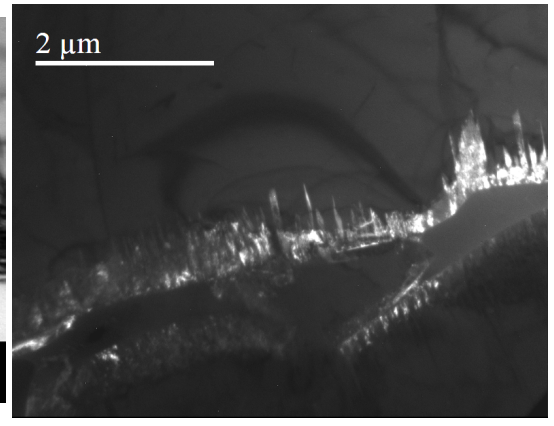

$\delta$ - hydrides in OR1, dark field

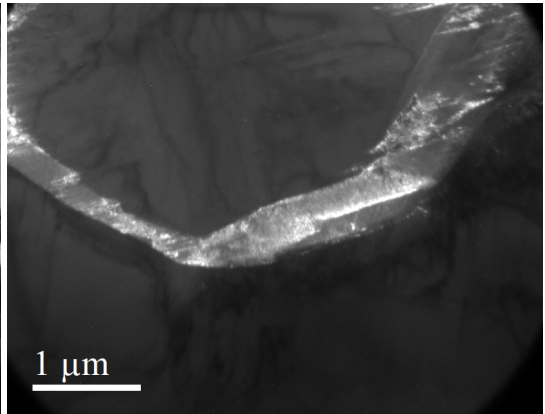

$\delta$ - hydrides in OR2, dark field

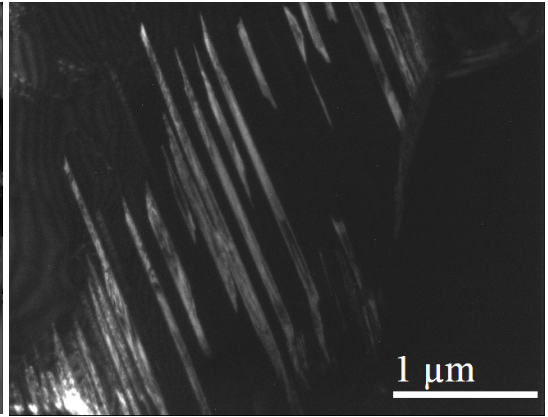

$\gamma$ - hydrides in OR2, dark field

Figure 9 : TEM analyses on hydrides formed at $50 \mu \mathrm{m}$-depth in titanium grade 23 after $96 \mathrm{~h}$ (regime III) of hydrogen charging by cathodic polarization at $-1.8 \mathrm{~V} / \mathrm{SCE}$ in artificial seawater 


\section{Discussion}

Despite a large difference between both microstructures of the alloys studied, similar behaviour were observed in term of hydrogen absorption (Figure $2)$. The absorption rate of hydrogen at applied potentials ranging from -0.8 to $-1.5 \mathrm{~V} / \mathrm{SCE}$ in artificial seawater is low in the range of our considered times $(<200 \mathrm{~h})$ with hydrogen concentration less than $100 \mathrm{wppm}$. This result is in good agreement with previous works. Absorptions of hydrogen up to $120 \mathrm{wppm}$ were identified at $-1.05 \mathrm{mV} / \mathrm{Ag} / \mathrm{AgCl}$ after 2 years of polarizations of grade 2 [6] and 100 wppm after 1 year of polarizations on grade 23 (stabilized at 90 wppm measured after 2 years) [7]. In opposite, for $-1.8 \mathrm{~V} / \mathrm{SCE}$, a largest increase of hydrogen has been identified. Four regimes were observed (Figure 2); stage IV corresponds to a pseudo saturation equal to $1000 \mathrm{wppm}$ for grade 2 and $2000 \mathrm{wppm}$ for grade 23 . Polarization curves of grade 2 and grade 23 in artificial sweater presents three domains, A from $-0.5 \mathrm{~V} / \mathrm{SCE}$ to $-1 \mathrm{~V} / \mathrm{SCE}$ then $\mathrm{B}$ up to $-1.5 \mathrm{~V} / \mathrm{ECS}$ and $\mathrm{C}$ from this value to more negatives potentials. Domains A and B restrict the hydrogen absorption because it is in competition with oxygen reduction and formation of Aragonite calcareous deposit on the surface. In domain C, there is the formation of inhomogeneous Brucite and Calcite. The peculiar kinetic modifications seen with the $-1.8 \mathrm{~V} / \mathrm{SCE}$ curve suggests surface modifications on samples. The calcareous deposit formation could be an explanation for the quasi-plateau of regime II. But after performing hydrogen charging in $\mathrm{NaCl}$ and in $\mathrm{H}_{2} \mathrm{SO}_{4}$, which don't produce calcareous deposits, this step is still present. It could also be caused by a modification of the behaviour of the titanium oxide film, as seen by Ohtsuka [8] and Vezvaie [9], which chemically change from $\mathrm{TiO}_{2}$ to $\mathrm{TiOOH}$ on cathodic polarization in neutral solutions. Therefore, Ohtsuka [8] also determined that on cathodic polarization in acidic solutions, the oxide $\mathrm{TiO}_{2}$ is reduce. Consequently, regimes I and II are only associated with hydrogen activity.

On the grade 2, a homogeneous nanostructures hydride layer in sub-surface was observed for 30h of polarization at -1.8V/SCE, Figure 6. This layer becomes massive at $72 \mathrm{~h}$. The quasi-plateau (regime II) could take his origins on the slow-down of hydrogen diffusion during the homogenisation of the hydride layer which present a two decades lower diffusion coefficient $\left(10^{-16} \mathrm{~m}^{2} / \mathrm{s}\right.$ in hydride at $\left.30^{\circ} \mathrm{C}[10,11]\right)$ than in $\alpha$-phase $\left(10^{-14} \mathrm{~m}^{2} / \mathrm{s}\right.$ in $\left.\alpha 30^{\circ} \mathrm{C}[12]\right)$. Hydride formation leads to volume expansion $(12,5-14 \%$ for $\gamma$-hydrides and $21-29 \%$ for $\delta$-hydrides [1]) which explain the evolution of roughness over time of grade 2, Figure 4. Even if a hydride layer forms, hydrides clusters were observed in the bulk. (Figure 6 and Figure 8). The structure of this grade 2 has a particularity; his grains are mostly with strong misorientations, which means a large fraction of random grain boundaries with high excess volume. This could form diffusion short-circuits and allow a part of hydrogen atoms to penetrate in all the bulk and form a large fraction of hydrides in stage III. To resume, four processes are in competition during the hydrogen charging: the growing of a hydride phase from the surface and three processes of the hydrogen diffusion (a first in the $\alpha$-phase, a second other in the hydride phase and third along the grains boundaries).

In the grade 23, first hydrides formation were identified on regime III, Figure 3, Figure 7, Figure 9. Therefore, AFM analyses, Figure 5, show a small evolution of the roughness even before these formations. Hydrogen solubility limits are from 20 to $100 \mathrm{wppm}$ in $\alpha$-phase at $25^{\circ} \mathrm{C}$ depending on sources $[1,13,14,15]$ and is much higher in $\beta$-phase. Regarding solubility limits of $\beta$-alloys and phase-diagrams of titanium, the solubility of hydrogen could reach around 5000 to $10000 \mathrm{wppm}$ at $25^{\circ} \mathrm{C}$ in $\beta$-phase $[13,14,16,17,18]$. Hydrogen diffuses also faster in $\beta$ alloys $[18]$ and is a $\beta$-stabilizer $[19,20$, $21]$. For these reasons, we can assume that hydrogen diffuse in $\beta$ until its solubility limit are reached (regime II). Before this point, $\beta$ growth and increases the roughness of the surface, then hydrogen cannot be absorbed by $\beta$ anymore (only $6 \%$ of the volume fraction of phases), which can cause the quasi-plateau of the regime II. In regime III, hydrides form first on interfaces and when they are saturated, hydrogen penetrates in $\alpha$-grains, quickly reach the low solubility limit of this phase and forms hydrides (Figure 7, Figure 9). The quantity of hydrogen being high in sub-surface allow the formation of intergranular and intragranular hydrides. Below, there is not enough hydrogen for the formation of intragranular hydrides and just intergranular are present. Deeper, no more hydrides are present because of the fewer hydrogen concentration. Hydrides and $\beta$-phase volume expansion explains the strong roughness's rise on regime III, Figure 5. This expansion cannot be accommodated in the bulk and induces long-range internal stresses.

Finally, the calcareous deposit becomes more compact with time, stabilized with the help of the roughness increase (this phenomenon has been studied to improve the stability of implants and prosthesis for biomedical purposes $[22,23,24]$ ), and lead to a decrease of the current intensity by adding resistance on the surface and could cause the stabilization of regime IV. The saturation of the sub-surface by hydrides also strongly decrease the absorption rate for both alloys.

\section{Conclusion}

Different kinetics of hydrogen absorption in grade 2 and grade 23 during hydrogen charging by cathodic polarization in artificial seawater have been highlighted. For our charging durations (until 200 hours), only cathodic polarizations of -1.6V/SCE and more negatives lead to a noticed hydrogen uptake. Kinetic variations of hydrogen absorption during polarizations at $-1.8 \mathrm{~V} / \mathrm{SCE}$ have been attributed first to a competition between the diffusion processes and the formation of hydrides for grade 2 and to the ingress of hydrogen in b-phase reaching the solubility limit for grade 23 , then to the growth of a large fraction of hydrides in the bulk. On longer durations the diminution of the current intensity is caused by the presence of a calcareous deposit and the saturation of sub-surface by hydrides. The formation of $\gamma$-hydrides have been localized in grade 2 as a layer that increases the surface roughness, then $\gamma$-hydrides in OR2 and $\delta$-hydrides in OR2 and OR 3 have been localized as clusters in the bulk. In grade 23 , hydrogen is absorbed by $\beta$ phase leading to a volume dilatation of this phase affecting the surface roughness. Then after reaching the hydrogen solubility limit of $\beta$-phase, first $\delta$ hydrides in OR 1 and OR 2 forms on interfaces $\alpha / \beta$ and $\alpha / \alpha$ and with more hydrogen, $\gamma$-hydrides in OR 2 forms in $\alpha$ grains. All these kinetics can affect the damage processes, which will be discussed in a further works.

\section{$\underline{\text { References }}$}

[1] E. Conforto, I. Guillot, X. Feaugas. 2017, Phil. Trans. R. Soc. A 375:20160417.

[2] X. Feaugas, D. Delafosse, Mechanics - Microstructure - Corrosion Coupling, Published by Elsevier Ltd. ch-9 (2019), 199-222.

[3] a) E. Conforto, D. Caillard, B.-O. Aronsson and P. Descouts (2004), Phil. Mag. 84(7), 631-645;

b) E. Conforto, B.-O. Aronsson, A. Salito C. Crestou and D. Caillard (2004), Mat. Sci. \& Eng. C 24, 611- 618.

[4] E. Conforto and D. Caillard (2007), Acta Materialia 55, 785-798.

[5] W. G. Burgers, 1934, Physica, 1, 561-586.

[6] L. Lunde and R. Nyborg, Sandefjord, Norway, 7-9 June 1993. 
[7] M. Seiersten and L. Lunde, 21ST international conference on offshore mechanics and arctic engineering, OMAE2002-28580, Oslo, Norway, June $23-28,2002$.

[8] T. Ohstuka, M. Masuda and N. Sato, J. Electrochemical Society, 134(10): 2406-2410.

[9] M. Vezvaie, J. J. Noë, Z. Tun and D.W. Shoesmith, Journal of The Electrochemical Society, 160 (9) C414-C422 (2013).

[10] B. Kappesser, H. Wipf. Journal de Physique IV Colloque, 1996, 06 (C8), pp.C8-73-C8-76.

[11] H. Wipf, B. Kappesser, R. Werner, Journal of Alloys and Compounds 310 (2000) 190-195.

[12] Y. Lu and P. Zhang, Journal of Applied Physics 113, 193502 (2013).

[13] J. Huez, PhD UTC, 1996.

[14] F. Manchester, A. San Martin, ASM International, Materials Park, OH, pp. 238-258, 2000

[15] D. Eliezer, E. Tal-Gutelmacher, C.E. Cross and Th. Boellinghauss, Mat. Sci. Eng. A 421, (2006), 200-207.

[16] H. Numakura and M. Coiwa, Acta Metall. 1984, 32, 1799-1807.

[17] W. M. Mueller, J. P. Blackledge, and G. G. Libowitz, Metal Hydrides, Academic Press, New York, NY, USA, 1968.

[18] H-J Christ, A. Senemmar, M. Decker and K. Prüßner, Sādhanā Vol. 28, Parts 3 \& 4, June/August 2003, pp. 453-465.

[19] Yves Combres, Techniques de l'ingénieur, M2355 V1, 10 juin 1997.

[20] B. De Gélas, M. Armand, L. Séraphin, R. Tricot, Techniques de l'ingénieur, M557 V1, 10 juillet 1976.

[21] M. Peters, J. Hemptenmacher, J. Kumpfert and C. Leyens, Titanium and Titanium Alloys. Fundamentals and Applications, ISBN: 3-527-30534-3, p. 1-36, 2003

[22] E. Conforto, D. Caillard, B.-O. Aronsson and P. Descouts, Philosophical Magazine, Vol. 84, No. 7, 631-645, 1 March 2004.

[23] Frank A. Müller, Lenka Müller, Daniel Caillard, Egle Conforto, Journal of Crystal Growth 304 (2007) 464-471.

[24] E. Conforto, D. Caillard, L. Müller, F.A. Müller, Acta Biomaterialia 4 (2008) 1934-1943. 